\title{
Plasma-Activated Vapor for Sanitization of Hands
}

\author{
Isam Osman, Aravind Ponukumati, Michael Vargas, Dipesh Bhakta, \\ Berk Ozoglu, \& Charles Bailey* \\ School of Biomedical Engineering, Science, and Health Systems, Drexel University, Philadelphia, \\ PA 19104 \\ *Address all correspondence to: Charles Bailey, School of Biomedical Engineering, Science, and Health Systems, Drexel \\ University, Philadelphia, PA 19104, E-mail: shicktopher@gmail.com
}

\begin{abstract}
Compliance with established hand hygiene protocols is extremely low in clinical units because these protocols mandate long hand-washing times. This phenomenon results in more numerous healthcare-associated infections and severely compromises the health of patients. Poor compliance is motivated by the hand-washing times required by soaps and sanitizers, which can be as long as 2 minutes. Cold atmospheric plasma is an alternative antimicrobial technology that can reduce the time required for sanitization to approximately $5 \mathrm{~s}$. However, despite many advantages, existing plasma devices generate ozone as a toxic byproduct in high concentrations, so there is a need for a plasma-based hand sterilization system that: (1) produces enough reactive oxygen and nitrogen chemical species to achieve a microbial kill rate that is able to compete with existing hand-sanitizing technology and (2) counteracts the conversion of plasma into ozone. The design presented here used water vapor to perform these functions and to stabilize reactive plasma species. The plasma system delivers a plasmaactivated water vapor mixture to a hand surface by the action of a humidifier that is much safer and more efficient than other plasma sanitization systems on the market. The operational prototype consists of three stages: ultrasonic water vapor generation, dielectric-barrier discharge plasma generation, and a dispensary tubing system. We have shown that the device is capable of disaggregating bacteria in $5 \mathrm{~s}$ with significant reductions in ozone concentrations through the use of water vapor.
\end{abstract}

KEY WORDS: plasma medicine, sanitization, healthcare-associated infections, ozone, hand hygiene

\section{INTRODUCTION}

Compliance with established hand hygiene protocols is as low as $43.2 \%$ in intensive care unit settings. ${ }^{1}$ This compliance rate is far below the $90 \%$ recommendation from the Joint Commission. ${ }^{2}$ Poor handwashing compliance has been associated with crosstransmission of healthcare-associated infections (HAIs) and heightened mortality rates in hospitals. The Centers for Disease Control and Prevention (CDC) has determined that one of the main reasons for substandard hand-washing compliance is the length of time required for these protocols; in fact, most physicians do not comply with the long hand-washing times required for effective sanitization. ${ }^{3}$ For example, proper sanitization using alcohol-based sanitizers (ABS) requires approximately $30 \mathrm{~s}$ and using antimicrobial hand soap requires at least $1 \mathrm{~min}$ in order to be effective. ${ }^{3}$ Neverthe- 
less, the average duration of hand washing for health care personnel remains at around 4.7-5.3 s (Fig. 1). ${ }^{3}$

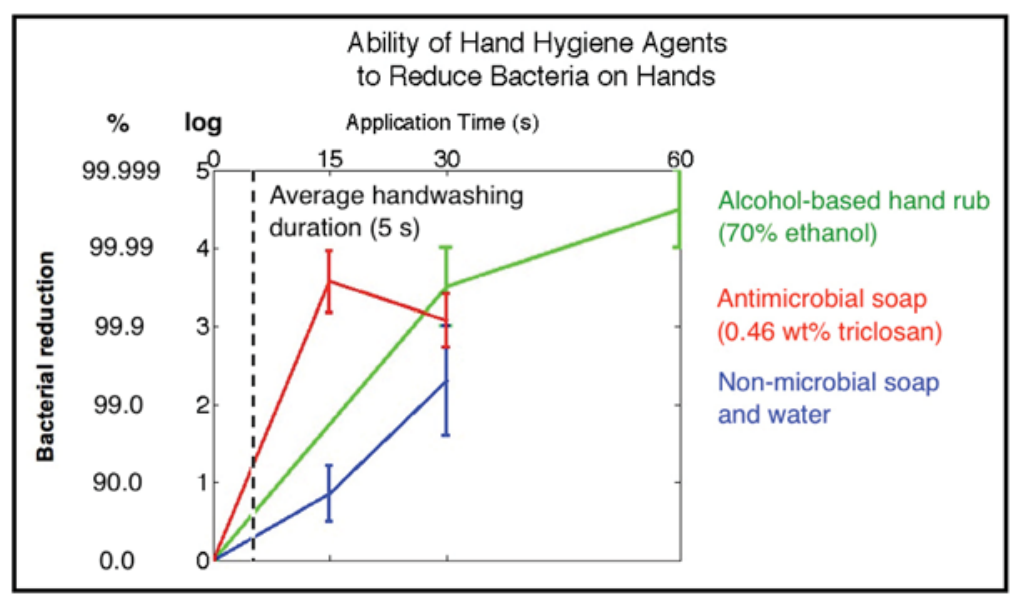

FIG. 1: Graphic of the average handwashing duration and bacterial reduction for three commonly used handwashing methods. Note the average handwashing duration of $5 \mathrm{~s}$ (dotted line).$^{4-6}$

Cold atmospheric plasma (CAP) sterilization is an alternative to commonly used sterilization techniques due to its many advantages: it is fast, efficient, and safe in terms of chemical, radiative, and thermal damage. ${ }^{7}$ Plasma can sterilize surfaces in less than 1 min and with a greater degree of bacterial inactivation than soaps. ${ }^{8,9}$ When water is used as a carrier for plasma, the mixture remains active on the scale of days, significantly longer than the time required to wash one's hands. Despite its promise, plasma sterilization has not seen widespread implementation in the clinical setting for several reasons.

First, the application of CAP for medical uses is quite new, which makes devices expensive to purchase..$^{10}$ The use of liquid water as a carrier has some disadvantages. When bacteria are submerged in plasma-activated water, "neither electrons nor ions can interact directly with the surface of the bacteria since these electrons or ions are strongly absorbed by the liquid." "Using liquid water as a carrier also hinders the ability of CAP to interact with bacteria.

Many plasma devices also suffer from the nonspecific generation of ozone, which is a naturally occurring side product of plasma. The reactive plasma species that have a short half-life may recombine or radicalize $\mathrm{O}_{2}$ as shown in Mechanism 1: generation of ozone from diatomic oxygen and reactive plasma species ${ }^{12}$ :

$$
\begin{aligned}
& \mathrm{O}_{2}^{-}+e^{-} \rightarrow 2 \mathrm{O}^{\top}+e^{-} \\
& \mathrm{O}^{\prime}+\mathrm{O}_{2}+M \rightarrow \mathrm{O}_{3}+M \text { (with } M=\mathrm{N}_{2} \text { or } \mathrm{O}_{2} \text { ) }
\end{aligned}
$$

Although ozone has been shown to have some antimicrobial properties, its formation requires the consumption of reactive plasma species. In addition, it is a powerful 
oxidant and damaging to respiratory and mucous tissues at minute levels. ${ }^{13}$ Although no extensive studies have been done on the dangers of ozone to humans, according to the $\mathrm{CDC}$, ozone is acutely hazardous at concentrations of $5 \mathrm{ppm} .{ }^{14}$ Plasma devices produce upwards of 100 ppm ozone..$^{8,9,15-17}$ Therefore, there is a need for a plasma sterilization system using an alternative delivery method that increases the effective plasma concentration and reduces or counteracts the conversion of plasma into ozone. In particular, such a device should have an ozone production of below $300 \mathrm{ppb}$ ozone, which is the permissible short-term exposure limit set by the Occupational Safety and Health Administration (OSHA). ${ }^{18}$

To reduce the ozone produced by a plasma device, water vapor can serve as an ozone scavenger. It may increase effective plasma concentrations by forming radical species that consume ozone through Mechanism 2: conversion of ozone molecules into ROS ${ }^{19}$ :

$$
\begin{gathered}
\mathrm{H}_{2} \mathrm{O}+\mathrm{e}-\rightarrow \mathrm{H}^{*}+\mathrm{HO}+\mathrm{e}- \\
\mathrm{H}^{\cdot}+\mathrm{O}_{3} \rightleftharpoons \mathrm{HO}+\mathrm{O}_{2} \\
\mathrm{HO}^{*}+\mathrm{O}_{3} \rightleftharpoons \mathrm{HO}_{2}+\mathrm{O}_{2} \\
\mathrm{HO}_{2}+\mathrm{O}_{3} \rightleftharpoons \mathrm{HO}^{*}+2 \mathrm{O}_{2}
\end{gathered}
$$

Stable water clusters also form readily in atmospheric conditions through the interaction of water vapor and ions, which are a key constituent of reactive plasma species. ${ }^{20}$ Because gaseous water vapor has a mean free path length 750 times longer than liquid water, it has an increased charge-carrying capacity and can increase the effective plasma concentration. ${ }^{21,22}$ Due to its natural interaction with ions in forming a thermodynamically stable structure, water vapor can also be used as a carrier for plasma particles. ${ }^{23}$ Given the attractiveness of using water vapor as a carrier and scavenger, a device was created that delivers stable, plasma-activated water vapor to a surface using a hand dispensary system.

\section{MATERIALS AND METHODS}

This prototype was designed with the purpose of providing a means to sanitize hands effectively in healthcare settings while catering to the average amount of time health care professional spend washing their hands. Unlike other conceptual plasma sanitization systems, this design utilizes water vapor to increase effective plasma concentrations and to scavenge the harmful ozone byproducts of plasma generation. This device achieves hand sanitization by utilizing a combination of plasma-activated air and water vapor. This device can be broken down into three key components: (1) water vapor is generated by an ultrasonic humidifier, (2) plasma is generated by dielectric-barrier discharge (DBD), and (3) the plasma/vapor mixture is applied onto the surface of hands (Fig. 2).

In the first stage, water vapor is generated using an ultrasonic humidifier (Pure n' Natural Travel Humidifier). The vibration of a small plate in the humidifier provides suf-

Volume 6, Issue 3-4, 2016 


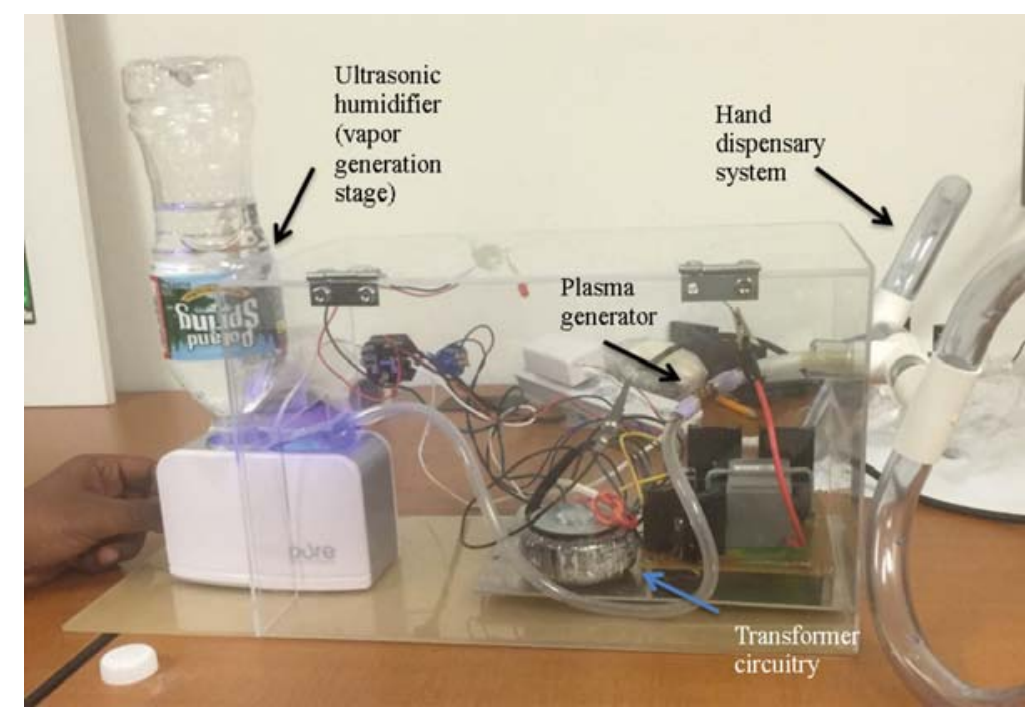

FIG. 2: Overview of the operational prototype. The stages have been labeled for clarity.

ficient energy to vaporize water an average rate of $2.7 \mathrm{oz} / \mathrm{h}$. The humidifier is designed to output a steady stream of water vapor with a single outlet, creating an air current that is directed toward the plasma generation stage using flexible $3 / 8$-inch PVC tubing (Fig. 3).

In the second stage, CAP is generated via DBD. The plasma generator was constructed previously at the Drexel Plasma Institute and is diagrammed in Fig. $4 .{ }^{24}$ The cylindrical high-voltage electrode surrounds the grounded electrode at a gap distance of $0.32 \mathrm{~cm}$ (1/8 inch). At this gap distance, according to Paschen's law, $10.24 \mathrm{kV}$ must be applied to induce ionization of air molecules at standard temperature and pressure conditions. The electrical components of the design are capable of transforming the 120 $\mathrm{V}_{\mathrm{AC}}$ output from a wall socket to a range of $4-25 \mathrm{kV}$ and $20 \mathrm{kHz}$, which is sufficient to ionize air molecules. The key component in accomplishing this high voltage is transformer winding (part no. CHT-0126G; Ramsey Electronics). The dielectric used is a 6.4 $\mathrm{mm}$ (1/4 inch) diameter quartz tube, with wall thickness of $\sim 0.05 \mathrm{~cm}(0.02 \mathrm{inch})$ and a length of $25 \mathrm{~mm}$ ( 1 inch). This quartz tube is connected to the 3/8-inch PVC tubing via a 3D-printed adapter. With the application of the high voltage to the electrodes, small electrical streamers form between the electrodes, generating reactive oxygen and nitrogen species. ${ }^{25}$ The incoming water vapor interacts with the charged plasma particles as described previously.

In the third stage, the particles maintain their forward velocity due to the air current generated by the humidifier. The particles are directed toward the hands via tubing and deposited directly on the surface of the skin via small orifices (Fig. 5). At this point, they interact with any present microorganisms and eliminate them. It is the user's responsibility to ensure adequate coverage of all surfaces of the hands by moving his or her hands throughout the $5 \mathrm{~s}$ of application, similar to washing hands. The diameter of each deposi- 
STEP 1

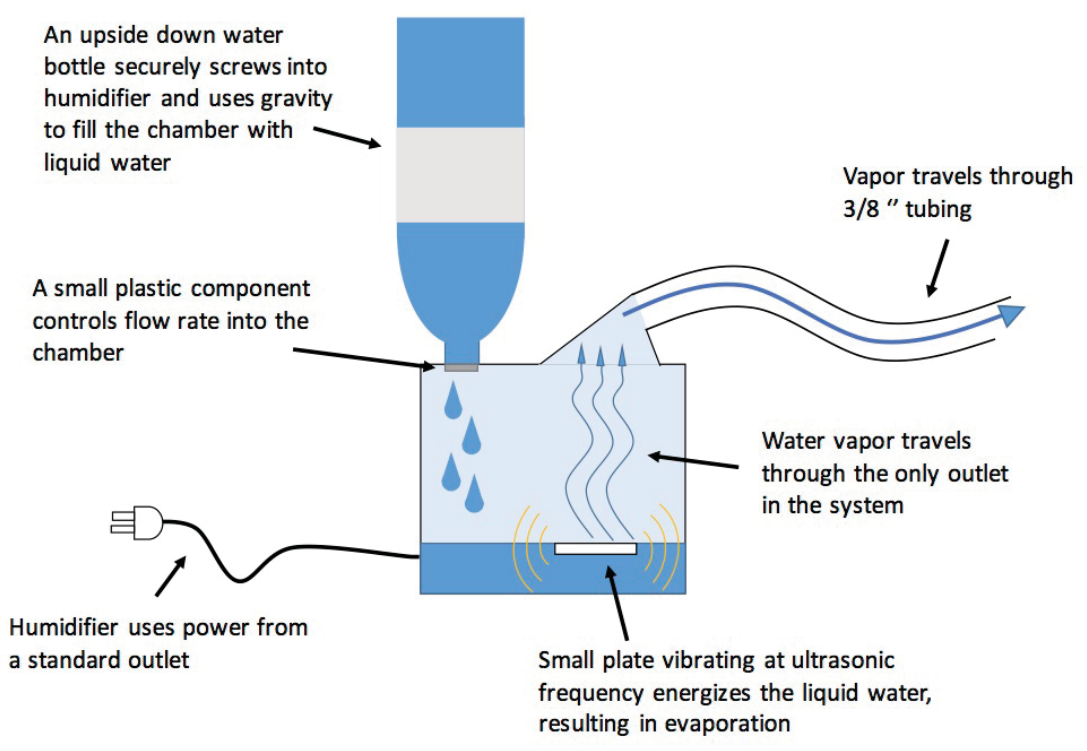

FIG. 3: Water vapor generation stage by ultrasonic humidification. The humidifier produces an average moisture output of $79.84 \mathrm{~mL} / \mathrm{h}$, corresponding to a volumetric flow rate of $3470 \mathrm{~L} / \mathrm{h}$. Flexible PVC of 3/8-inch outer diameter secures the humidifier to the plasma generator.

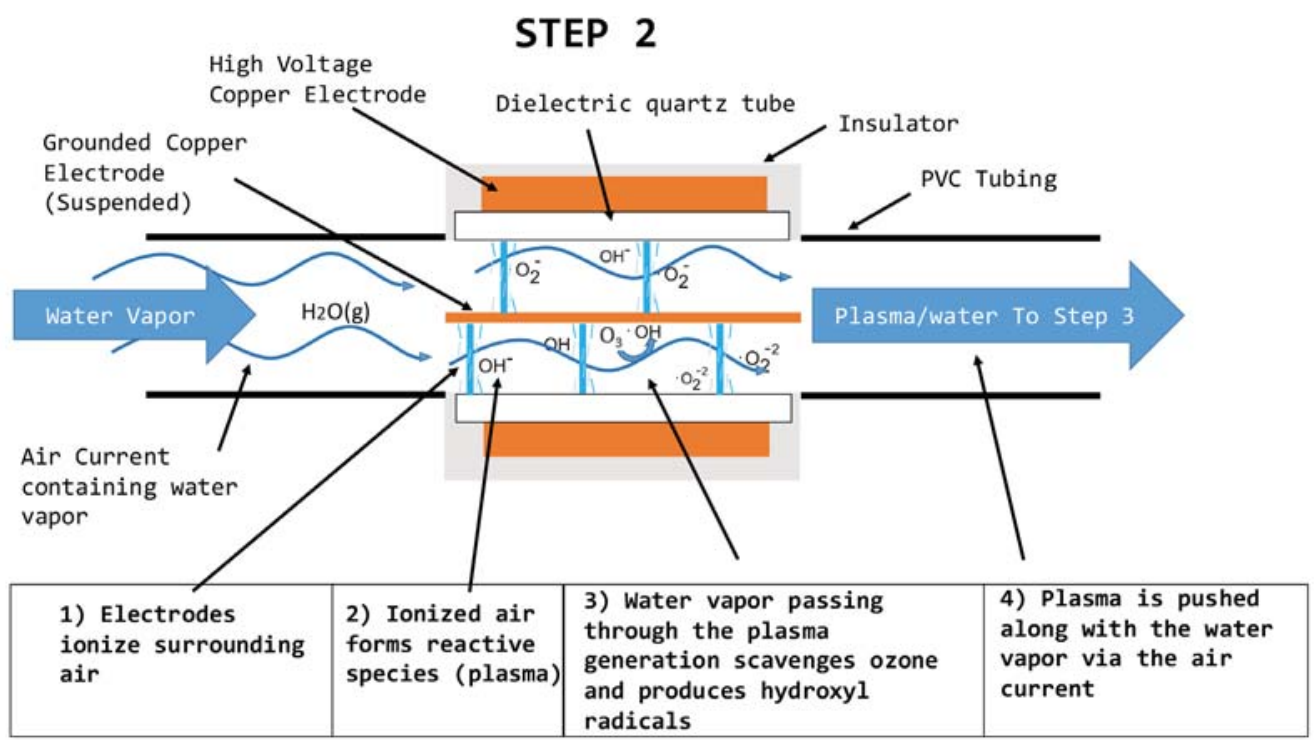

FIG. 4: Cross-sectional diagram of the plasma generation phase. There are two copper electrodes: the high-voltage electrode wraps around the outer edge of the quartz tube and the lowvoltage electrode is suspended at the center. Water vapor generated in the humidification stage is driven through this stage by an air current.

Volume 6, Issue 3-4, 2016 


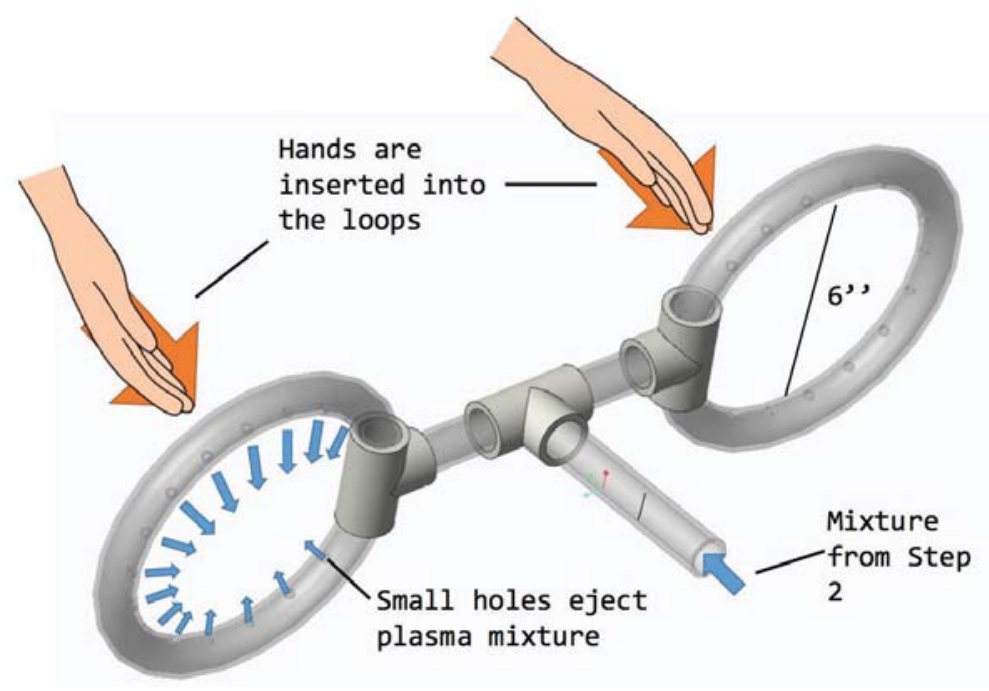

FIG. 5: Hand dispensary tubing system. The output from step 2 contains plasma-treated water vapor clusters, which are passed through the PVC tubing and deposited onto the user's hands through 18 3/16-inch holes along the inner edge of the rings.

tion ring is 6 inches because the average width of a human hand is slightly greater than 3 inches for males: this ring size is large enough for the hand to fit comfortably, but small enough for sufficient coverage. The user is requested to rotate their hands $180^{\circ}$ clockwise and counterclockwise to provide a more even coverage to all parts of the hand.

\section{RESULTS AND DISCUSSION}

To develop a successful design, the first requirement was for the plasma-activated vapor device to kill bacteria as effectively as current sanitization methods, but within $5 \mathrm{~s}$. A test of the antimicrobial function of the device was considered successful if there was disaggregation, or reduction in E. coli colony area, after plasma treatment comparable to ABS- and soap-treated controls. E. coli bacteria have been used to test the efficacy of DBD plasma in the past and bacterial disaggregation is a metric that has been used to evaluate the efficacy of sanitization methods such as soaps..$^{24,26}$ In the control group, E. coli bacteria (16000:1 dilution) were spread onto agar plates using the streak method and incubated for $24 \mathrm{~h}$. Positive controls were then treated with mock antimicrobial soap ( $0.2 \%$ SDS) and ABS ( $8.75 \%$ ethanol solution). The experimental plates were treated with plasma-activated vapor produced at voltages between 4 and $22 \mathrm{kV}$ and for time periods ranging from 5 to $20 \mathrm{~s}$. It was observed that all positive control and experimental plates except the $4 \mathrm{kV}$ application had a significantly lower average colony area than the control plate (Fig. 6). This is consistent with the bactericidal properties of ABS and antimicrobial soaps and confirms that these treatments do interact with E. coli. Although a $4 \mathrm{kV}$ application was ineffective because no plasma is produced below the breakdown 


\section{Effect of Plasma Application on E. coli Colony} Area

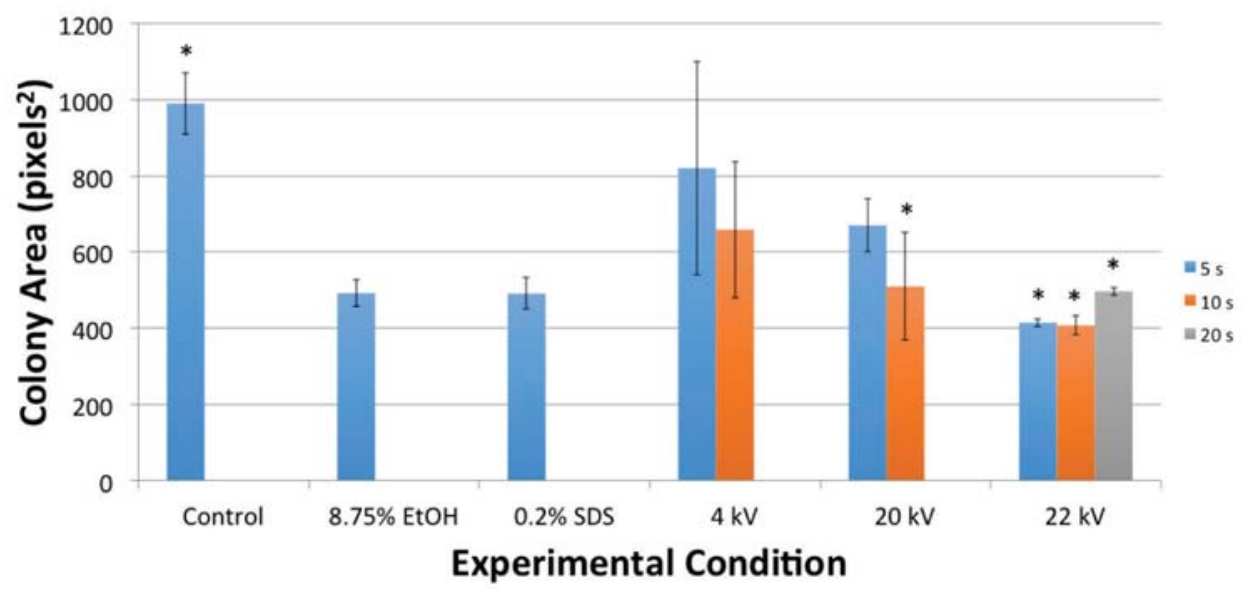

FIG. 6: Effect of plasma application on E. coli colony area. Various controls were implemented for current hand sanitization methods, three voltage settings were used, and the application time ranged from 5 to $20 \mathrm{~s}$. Asterisks denote equivalent or lower colony area compared with ethanol and sodium dodecyl sulfate (SDS) controls $(p<0.05)$.

voltage of air, the test was successful in showing that plasma treatments reduce colony area significantly compared with an untreated control. Importantly, the difference in colony area between the positive controls and a $5 \mathrm{~s}$ application of plasma produced at 22 $\mathrm{kV}$ was statistically insignificant $(p<0.05)$.

The device was also considered to meet specifications if there was a reduction in ozone production below $300 \mathrm{ppb}$ after the addition of the vapor generation stage. An ozone monitor (2B Model 202, InDevR, Boulder, CO) was used to measure the concentration of ozone at the output of the plasma generator. A calibration measurement was taken with the device turned off, revealing an atmospheric ozone concentration of approximately $10 \mathrm{ppb}$. A total of six different experimental conditions were tested, from 4 to $22 \mathrm{kV}$ and with and without additional humidification (Fig. 7). A two-sample $t$ test was performed to check for statistical differences between the groups. It was concluded that the addition of water vapor reduced ozone concentrations significantly at the 4 and $22 \mathrm{kV}$ voltages. Analyses were not performed for the $20 \mathrm{kV}$ voltage setting because data were only obtained from one trial. In the test conducted at $20 \mathrm{kV}$, we saw an increase in ozone production when water vapor was introduced, which was atypical and inconsistent with all of the other tests conducted. This could be attributed to the lack of testing trials conducted at that specific voltage and further studies must be done. It may be concluded that the administered volumetric flow of water vapor is enough to scavenge oxygen radicals and prevent ozone generation significantly during the device's operation.

Volume 6, Issue 3-4, 2016 


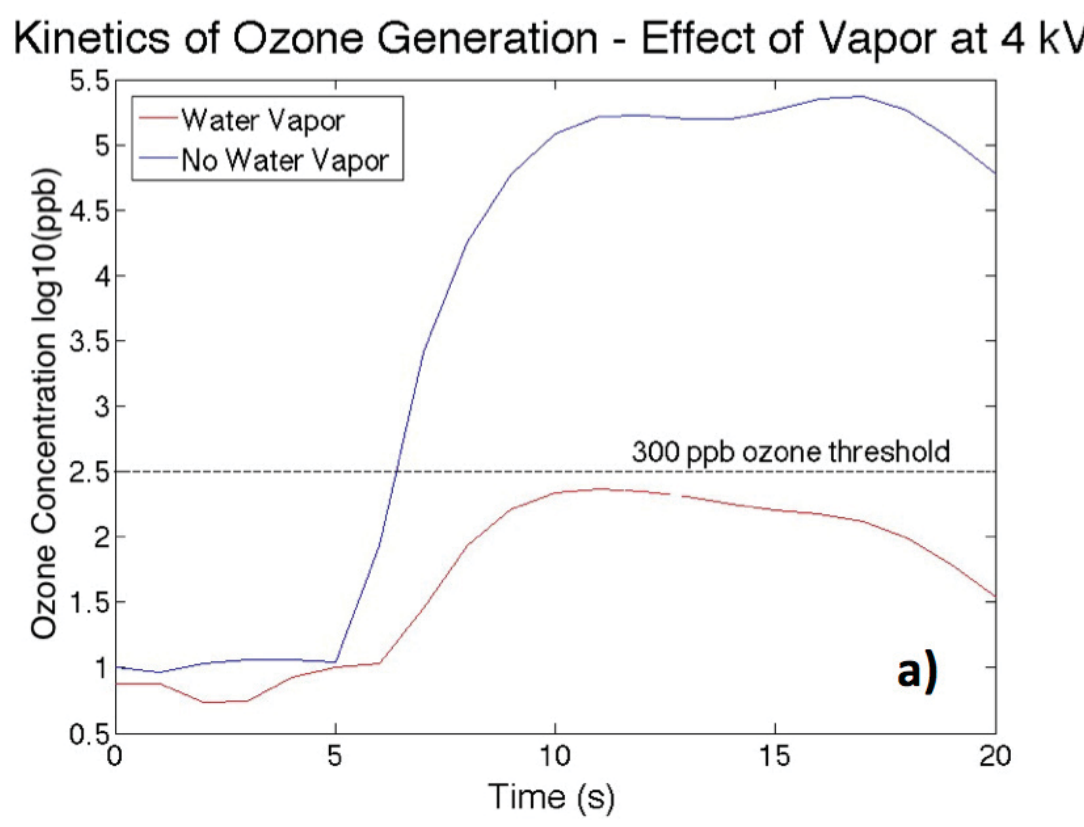

Effect of Device Parameters on Ozone Production

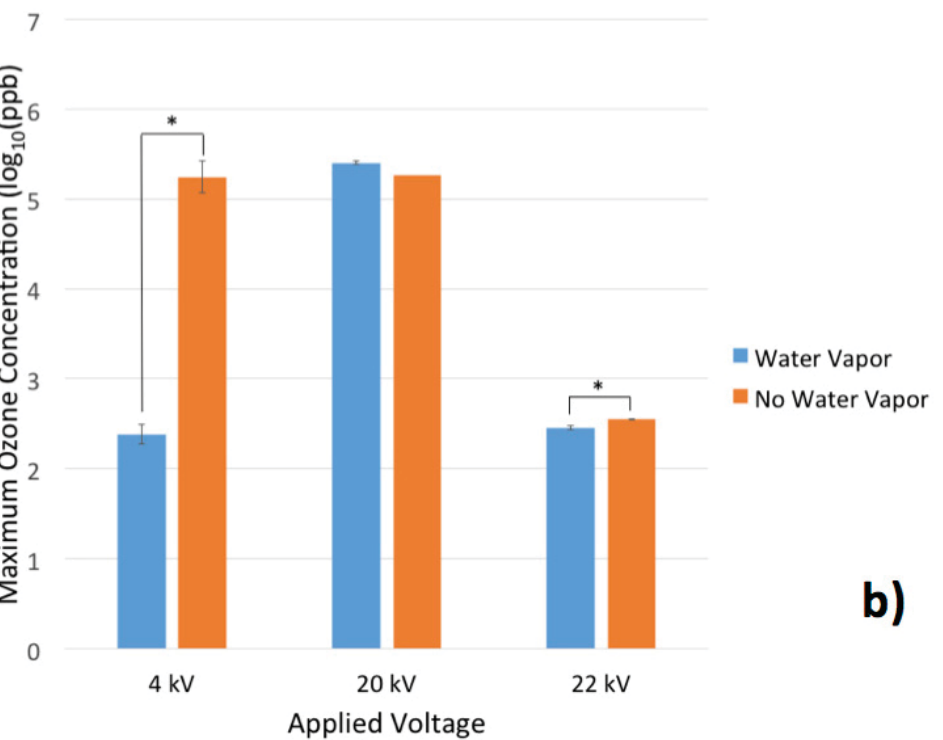

FIG. 7: (a) Kinetics of ozone generation at a $4 \mathrm{kV}$ operating voltage with and without humidification. The dotted line represents the $300 \mathrm{ppb}$ threshold and a steady delivery of water vapor keeps ozone concentrations below this level at all time points. (b) Ozone production of the plasma device at various applied voltages and in the presence or absence of humidification. Asterisks denote a statistically significant difference in ozone concentration after administration of water vapor. 


\section{CONCLUSION}

Based on the testing results, the plasma device successfully achieves a bacterial colony disaggregation comparable to soaps and ABS in $5 \mathrm{~s}$. It also produces water vapor that acts both as a carrier and ozone scavenger, reducing ozone concentrations to below the 300 ppb OSHA threshold.

CAP for hand sanitization purposes has distinct advantages over its alcohol- and soap-based counterparts. Because the sanitization time of plasma-activated vapor is comparable to the average hand-washing time of healthcare providers, an increase in hand hygiene compliance and a decreased incidence of HAIs is expected. Studies have shown that mortality, cost, and length of hospital stays were significantly higher in patients with HAIs compared with patients without HAIs. ${ }^{27}$ However, current DBD plasma products have undesirable characteristics, such as the production of significant amounts of ozone and use of carriers that interfere with bacterial inactivation properties. Conversely, the device described here uses water vapor to counteract ozone production while stabilizing reactive plasma species to be applied to the hand.

To better the design and mitigate some of the risks that are associated with ozone, a fan exhaust system may be implemented to siphon ozone out of the dispensary tubing and into a disposal system. The circuitry seen in Fig. 2 may also be better isolated from the vapor components as a prophylactic measure against leakage. Optimization of the geometry of the hand dispensary system is also highly recommended and specific tests may be performed to assess the hand surface coverage of plasma-activated vapor. Finally, integration of a "smart" feedback system will allow for constant monitoring of the quality of plasma production. Using modalities such as electrical conductivity, optical spectra, and acoustic emission, the user can remain informed throughout the device's runtime. In summary, we developed a device that uses water vapor as an ozone scavenger and a carrier molecule for CAP delivery to human hands.

\section{REFERENCES}

1. Sharma S, Puri S, Sharma S, Whig J. Hand hygiene compliance in the intensive care units of a tertiary care hospital. Indian J Community Med. 2011;36:217-221.

2. Shabot M, Chassin MR, France A, Innuria J, Kendrick J, Schmaltz SP. Using the targeted solutions tool to improve hand hygiene compliance is associated with decreased health care-associated infections. Jt Comm J Qual Patient Saf. 2016;42:6-17.

3. Boyce JM, Pittet D; Healthcare Infection Control Practices Advisory Committee; HICPAC/SHEA/ APIC/IDSA Hand Hygiene Task Force. Guideline for hand hygiene in health-care settings. Recommendations of the Healthcare Infection Control Practices Advisory Committee and the HIPAC/SHEA/ APIC/IDSA Hand Hygiene Task Force. Am J Infect Control. 2002;30:S1-S46.

4. Figueiredo, AE, de Siqueira SL, Poli-de-Figueiredo CE, d'Avila DO. Hand hygiene in peritoneal dialysis patients: a comparison of two techniques. Perit Dial Int. 2013;33:655-661.

5. Amin N, Pickering AJ, Ram PK, Unicomb L, Najnin N, Homaira N, Ashraf S, Abedin J, Islam MS, Luby SP. Microbiological evaluation of the efficacy of soapy water to clean hands: a randomized, noninferiority field trial. Am J Trop Med Hyg. 2014;91:415-423.

6. Fischler GE, Fuls JL, Dail EW, Duran MH, Rodgers ND, Waggoner AL. Effect of hand wash agents

Volume 6, Issue 3-4, 2016 
on controlling the transmission of pathogenic bacteria from hands to food. J Food Prot. 2007;70: 2873-2877.

7. Stapelmann K, Fiebrandt M, Raguse M, Awakowicz P, Reitz G, Moeller R. Utilization of low-pressure plasma to inactivate bacterial spores on stainless steel screws. Astrobiology. 2013;13:597-606.

8. Mastanaiah N, Banerjee P, Johnson J, Roy S. Examining the role of ozone in surface plasma sterilization using dielectric barrier discharge (DBD) plasma. Plasma Processes and Polymers. 2013;10:1120-1133.

9. Maisch T, Shimizu T, Isbary G, Heinlin J, Karrer S, Klampfl TG, Zimmermann JL. Contact-free inactivation of Candida albicans biofilms by cold atmospheric air plasma. Appl Environ Microbiol. 2012;78:4242-4247.

10. Rutala WA, Weber DJ. New disinfection and sterilization methods. Emerg Infect Dis. 2001;7:348-353.

11. Park, JH, Kumar N, Park DH, Yusupov M, Neyts EC, Verlackt CCW, Bogaerts A, Kang MH, Uhm HS, Choi EH, Attri P. A comparative study for the inactivation of multidrug resistance bacteria using dielectric barrier discharge and nano-second pulsed plasma. scientific reports. Sci Rep. 2015;5:13849

12. Ayrault C, Barrault J, Blin-Simiand N, Jorand F, Pasquiers S, Rousseau A, Tatibouet JM. Oxidation of 2-heptanone in air by a DBD-type plasma generated within a honeycomb monolith supported Pt-based catalyst. Catalysis Today. 2004;89:75-81.

13. Rasplicka D. Ozone in the air: ozone levels and their effects. Ozoneservices; YEAR [serial on the Internet]. Available from: http://www.ozoneservices.com/articles/007.htm.

14. National Institute for Occupational Safety and Health (NIOSH), Centers for Disease Control and Prevention [serial on the Internet]. Ozone; 1994 May. Available from: http://www.cdc.gov/niosh/ idlh/10028156.html

15. Kowalski W, Bahnfleth W, Whittam T. Bactericidal effects of high airborne ozone concentrations on Escherichia coli and Staphylococcus aureus. Ozone: Science \& Engineering. 1998;20:205-221.

16. Shimizu T, Sakiyama Y, Graves DB, Zimmerman JL, Morfill GE. The dynamics of ozone generation and mode transition in air surface micro-discharge plasma at atmospheric pressure. New J Phys. 2012;14:103028.

17. Boekema B, Vlig M, Guijt D, Hijnen K, Hofmann S, Smits P, Sobota A, van Veldhuizen EM, Bruggeman P, Middelkoop E. A new flexible DBD device for treating infected wounds: in vitro and ex vivo evaluation and comparison with a RF argon plasma jet. J Phys D Appl Phys. 2015;49:044001.

18. Department of Industrial Relations. Table AC1 - Permissible Exposure Limits For Chemical Contaminants. Occupational Safety and Health Administration, n.d. Web.

19. Trizio I, Sardella E, Francioso E, Dilecce G, Rizzi V, Cosma P, Gristina R. Investigation of air-DBD effects on biological liquids for in vitro studies on eukaryotic cells. Clin Plasma Med. 2015;3:62-71.

20. Zidi ZS. On the stability of ion water clusters at atmospheric conditions: Open system Monte Carlo simulation. J Chem Phys. 2012;137:124107.

21. O'Connell D, Cox LJ, Hyland WB, Mcmahon SJ, Reuter S, Graham WG, Gans T, Currell FJ. Cold atmospheric pressure plasma jet interactions with plasmid DNA. Appl Phys Lett [serial on the Internet]; 2011. Available from: http://scitation.aip.org/content/aip/journal/apl/98/4/10.1063/1.3521502.

22. Lurexlounge School Physics: Mean Free Path [serial on the Internet]; 2016 Mar. Available from: http:// www.schoolphysics.co.uk/age14-16/Matter/text/Mean_free_path/index.html.

23. Fehsenfeld F, Ferguson E. Origin of water cluster ions in the D region. J Geophys Res. 1969;74: 2217-2222.

24. Bailey C, Pemmaraju K, Phan M, Radhakrishnan A, Thomas A. Development of nonthermal plasmaassisted hand sanitization. Plasma Med. 2014;4:221-230.

25. Graves D. Reactive species from cold atmospheric plasma: implications for cancer therapy. Plasma Processes and Polymers. 2014;11:1120-1127.

26. Shafa F, Salton MRJ. Disaggregation of bacterial cell walls by anionic detergents. J Gen Microbiol. 1960;23.1:137-141.

27. Lazarus HM. Trauma patient hospital-associated infections: risks and outcomes. National Center for Biotechnology Information. U.S. National Library of Medicine, n.d. 2016 Oct 28. 
28. Glance LG, Stone PW, Mukamel DB, Dick AW. Increases in mortality, length of stay, and cost associated with hospital-acquired infections in trauma patients. Arch Surg. 2011;146.7:794-801.

29. Scott R. The direct medical costs of healthcare-associated infections in US hospitals and the benefits of prevention. Atlanta: Centers for Disease Control and Prevention; 2009.

30. Snopes. Acid Slip: Coca-Cola. Available from: http://www.snopes.com/cokelore/acid.asp.

31. Stone PW, Hasan S, Quiros D, Larson EL. Effect of guideline implementation on costs of hand hygiene. Nursing Economics. 2007;25:279-284.

Volume 6, Issue 3-4, 2016 